\title{
Aerobic Post-treatment of Different Anaerobically Digested Palm Oil Mill Effluent (POME)
}

\author{
Kian Weng Chou, Siew Wei Tan, Norhashimah Morad, Teng Tjoon Tow, Mohd Omar Abdul Kadir, \\ and Norli Ismail
}

\begin{abstract}
This study presents an investigation of the effect of aerobic post-treatment on different anaerobically digested palm oil mill effluent (POME) using lab scale aerobic digesters. Anaerobically digested POME was collected from anaerobic digesters operated at room temperature, mesophilic and thermophilic conditions, respectively. The experimental results showed the performance of each aerobic digester in term of chemical oxygen demand (COD), biodegradation rate, TSS and VSS removal. Room temperature digested POME was slightly more accessible to COD, TSS and VSS removal than others; whereas thermophilic digested POME was easier to be biodegraded than others.
\end{abstract}

Index Terms-Aerobic, palm oil mill effluent (POME), post-treatment.

\section{INTRODUCTION}

Malaysia has adopted wet process in palm oil milling for large scale production of crude palm oil (CPO). Approximately 5 to 7 tonnes of water are required to produce one tone of CPO, and more than half of this water ends up as palm oil mill effluent (POME) [1]. POME when fresh, it is a thick brownish colloidal mixture of water, oil and solids which are mainly debris from palm mesocarp. Currently, anaerobic-aerobic treatment by open ponding system is the most common method adopted in Malaysia to treat the high organic strength POME. This treatment system requires a vast area to accommodate a series of different facilities such as de-oiling tank, holding/equalization ponds, acidification pond, facultative-anaerobic ponds, aerobic ponds and polishing pond. Along with this, it has other disadvantages including long hydraulic retention time, greenhouse gaseous emission and foul smell. However, the conventional poor managed treatment system is difficult to meet local discharge standard [2]. Well controlled closed treatment systems are gaining attraction toward local palm oil mills due to it benefits from carbon emission reduction by methane recovery and utilization.

At present, most of the closed anaerobic digestion systems treating POME are operating at ambient temperature (without control) and only very few are controlled in temperature range. POME is discharged at temperature about 80 tp $90{ }^{\circ} \mathrm{C}$ and this makes anaerobic digestion of POME at mesophilic and

Manuscript received April 23, 2015; revised September 1, 2015. This work was supported by the Research University Grant (RUI) 1001/PTEKIND/814147.

The authors are with Environmental Technology Division, School of Industrial Technology, Universiti Sains Malaysia, 11800 Minden, Pulau Pinang, Malaysia (e-mail: norlii@usm.my). thermophilic temperature feasible. Both mesophilic and thermophilic anaerobic digestion of POME using different treatment system were extensively investigated [1]. Generally, thermophilic digestion able to tolerate hogher organic loading and to produce more methane compared to mesophilic digestion.

Conversely, there is insufficient of literature regarding the aerobic post-treatment of anaerobically digested POME. However, activated sludge reactor [3] and sequencing batch reactor [4], [5] were proposed to be used as post-treatment after anaerobic digestion of POME. Vijayaraghavan et al. [3] investigated aerobic post-treatment of anaerobically digested POME and diluted raw POME using activated sludge reactor with a fixed biomass concentration of $3900 \mathrm{mg} / \mathrm{L}$. The aerobic treatment reduced 98 and $93 \%$ of influent COD and BOD, respectively, at HRT of 60 hours. However, the influent COD and BOD concentration was only 3908 and $1720 \mathrm{mg} / \mathrm{L}$, respectively, which is very different to literature [4], [5]. Therefore, the feasibility of application and performance of activated sludge reactor treating high organic strength anaerobically digested POME remains unclear. Later, Chan et al. [4] shows the sequencing batch reactor is an effective post-treatment of anaerobically digested POME, which can achieve COD, BOD and TSS removal, ranging from 91 to $96 \%, 92$ to $99 \%$ and 94 to $99 \%$, respectively. At optimum conditions, the treated effluent quality was below local discharge limit, in terms of BOD, TSS, $\mathrm{pH}$ and TN. The effects of temperature on aerobic treatment of anaerobically digested POME were investigated by Chan et al. [5]. The results show that the performance of sequencing batch reactor was better at mesophilic temperature $\left(28{ }^{\circ} \mathrm{C}\right)$ compared to thermophilic temperature $\left(55^{\circ} \mathrm{C}\right)$. They observed that the COD, BOD and TSS concentration of treated effluent was increased with temperature.

To our knowledge, aerobic treatment of mesophilic and thermophilic digested POME has not yet been investigated and there is the need of deeper efforts in comparing the performance of these treatments. Thus, the objective of this study is to investigate the aerobic treatment of different temperature digested POME.

\section{MATERIALS AND MeTHODOLOGY}

\section{A. Sample Collection}

Three types of anaerobically digested POME, viz. R, M and $\mathrm{T}$ were used in this study:

1) $\mathrm{R}$ refers to anaerobically digested POME collected from 
an existing lab scale facultative-anaerobic digester operating at room temperature $\left(28 \pm 2{ }^{\circ} \mathrm{C}\right)$ with HRT of $50-60$ days and working volume of $20 \mathrm{~L}$. The digester was daily fed with raw POME and manual mixed to mimic the conventional facultative-anaerobic treatment condition in palm oil mill;

2) $\mathrm{M}$ and $\mathrm{T}$ refer to anaerobically digested POME collected from existing lab scale anaerobic digester with HRT of 16 - 20 days, operating at mesophilic temperature $\left(35^{\circ} \mathrm{C}\right)$ and thermophilic temperature $\left(55^{\circ} \mathrm{C}\right)$, respectively. Both digesters were daily fed with raw POME by using peristaltic pump. Mixing (150 rpm, $15 \mathrm{~min} / 165 \mathrm{~min}$ ) was provided by an overhead stirrer installed on the top of each digester.

All samples were stored in refrigerator at $4{ }^{\circ} \mathrm{C}$ to minimize further biodegradation due to microbial action. The characteristics of all anaerobically digested POME were analyzed and summarized in Table I.

TABLE I: CHARACTERISTICS OF DIFFERENT ANAEROBICALLY DIGESTED POME

\begin{tabular}{|c|c|c|c|c|c|c|c|c|c|}
\hline \multirow{2}{*}{ Parameters } & \multicolumn{3}{|c|}{$\mathrm{R}$} & \multicolumn{3}{|c|}{ M } & \multicolumn{3}{|c|}{$\mathrm{T}$} \\
\hline & Min. & Max. & Mean \pm SD & Min. & Max. & Mean \pm SD & Min. & Max. & Mean \pm SD \\
\hline $\mathrm{pH}$ & 7.5 & 7.7 & $7.6 \pm 0.1$ & 7.6 & 7.8 & $7.7 \pm 0.1$ & 7.6 & 7.8 & $7.7 \pm 0.1$ \\
\hline $\mathrm{COD}, \mathrm{g} / \mathrm{L}$ & 7.84 & 12.62 & $10.60 \pm 1.61$ & 8.53 & 11.18 & $10.27 \pm 0.63$ & 6.63 & 11.93 & $9.22 \pm 1.54$ \\
\hline TSS, g/L & 3.76 & 8.24 & $6.15 \pm 1.75$ & 4.68 & 8.16 & $6.95 \pm 1.17$ & 3.04 & 6.90 & $4.87 \pm 1.17$ \\
\hline VSS, g/L & 1.56 & 5.52 & $3.99 \pm 1.30$ & 1.84 & 5.28 & $4.17 \pm 1.15$ & 1.36 & 4.36 & $3.12 \pm 1.06$ \\
\hline
\end{tabular}

\section{B. Experimental Setup}

Three $2 \mathrm{~L}$ borosilicate glass laboratory bottles with effective working volume of $1.8 \mathrm{~L}$ were used as aerobic digesters, viz. AeD-R, AeD-M and AeD-T, which corresponding to aerobic digester treating $\mathrm{R}, \mathrm{M}$ and $\mathrm{T}$, respectively. All aerobic digesters were operated at room temperature $\left(28 \pm 2^{\circ} \mathrm{C}\right)$. An aquarium air pump with total air flow rate of $4.0-4.4 \mathrm{~L} / \mathrm{min}$ was used to supply air through plastic air stone diffusers that was located above the base of each aerobic digester. Semi-continuous mixing (15 min/45 min) was achieved by using a magnetic stirring plate to enhance homogeneity of the mixture. All aerobic digesters were covered with aluminum foil to minimize water lost due to aeration and evaporation.

\section{Experimental Procedures}

Experiments were started with biological seeding of $1.8 \mathrm{~L}$ different inoculum into each aerobic digester. In this experiment, acclimatization phase of each aerobic digester was neglected because the inoculums were obtained from existing lab scale aerobic digesters that already operated at steady state condition for more than 6 months. After that, the experiments were carried out at different HRT and OLR. Distilled water was added into each anaerobic digester before withdrawal of sample to maintain a constant working volume. One hour of settling time was allowed to obtain supernatant. Both mixed effluent and supernatant were analyzed.

\section{Chemical Analysis}

The chemical oxygen demand (COD) of samples was determined according to colorimetric method (HACH Method 8000) which is USEPA approved for wastewater analysis. Total suspended solids (TSS) and volatile suspended solids (VSS) were determined according to Standard Method $2540 \mathrm{D}$ and $\mathrm{E}$, respectively. $\mathrm{pH}$ and temperature were measured by using a HACH Sension3 $\mathrm{pH}$ meter with temperature probe. Dissolved oxygen (DO) was measured by using a DO meter (YSI model 5000, USA).

\section{RESULTS AND DISCUSSION}

The operating conditions of each aerobic digester were summarized in Table II. All aerobic digesters were operated in parallel at HRT of 18 days, 12 days, 9 days and 7.2 days which equivalent to feeding rate of $100 \mathrm{~mL} / \mathrm{d}, 150 \mathrm{~mL} /$ day, $200 \mathrm{~mL} /$ day and $250 \mathrm{~mL} /$ day, respectively. The feeding rate was stepwise increased to minimize organic shock loading in aerobic digesters. The $\mathrm{pH}$ was left unregulated in this experiment, however the aerobic microorganisms seems able to self-adjust to its optimum $\mathrm{pH}$ range and remained constant at 8.9 to 9.0. The results are supported by previous study [4], [5] which showed that the COD removal of aerobic system were more than $90 \%$ although the operating $\mathrm{pH}$ were between 7.5 and 9.2. Along the experimental period, the sludge bulking and foaming problems due to overgrowth of the filamentous microorganisms are not encountered due to high DO concentration [4], recorded to be in the range of 3.83 to $5.99 \mathrm{mg} / \mathrm{L}$ in all aerobic digesters, which is greater than adequate concentration of $2 \mathrm{mg} / \mathrm{L}$ for an aerobic biological system [6]. Due to the different operating conditions in anaerobic digestion, the fluctuations in COD, TSS and VSS concentrations in different digested POME (Table I) along the experimental period were noticed. This may contribute a minor effect on each aerobic digester as the OLR was not inclined in same ratio as shown in Table II. However, this study was not designed to evaluate the corresponding effect hence it remains unclear. Generally, the MLVSS represents the microbiological suspension in the biological wastewater treatment plant because the microbial cellular materials are volatilizes at $550{ }^{\circ} \mathrm{C}$. The $\mathrm{F} / \mathrm{M}$ ratio of 0.13 to $0.46 \mathrm{~g} \mathrm{COD} / \mathrm{g}$ MLVSS applied in this study are high due to the relatively lower MLVSS concentration compared to previous studies using sequencing batch reactors [4], [5] where the mixed liquor was allowed to settle for two hours before the clarified supernatant was discharged from the reactor. Therefore, the MLVSS could be controlled at a desired concentration to optimize the process performance. In this study, the HRT is equal to the solid retention time therefore the completed mixing before effluent withdrawal flushed out both degraded and undegraded solids.

Theoretically, the increase of OLR will lead to lower COD removal after reaching the maximum level [4]. In this study, the COD removal determination was based on the supernatant after settling of one hour. As shown in Fig. 1 (a), (b) and (c), 
the COD removals of all aerobic digesters were less sensitive to the increasing OLR applied in this experiment. The COD removals observed along the experiment were $84.6 \%$ to $92.9 \%, 74.8 \%$ to $84.8 \&$ and $77.6 \%$ to $88.8 \%$ for AeD-R, AeD-M and AeD-T respectively. The COD remained in treated effluent supernatant of AeD-R, AeD-M and AeD-T were 824 to $1308 \mathrm{mg} / \mathrm{L}, 1959$ to $2610 \mathrm{mg} / \mathrm{L}$ and 1143 to 1779 $\mathrm{mg} / \mathrm{L}$ respectively. The discharge of treated effluent supernatant with high COD concentration might deplete surface water quality although COD is not included in local discharge standard. Nevertheless, AeD-R demonstrated better COD removal than AeD-M and AeD-T. Chan et al. [4] observed a higher COD removal as a result of higher MLVSS concentration and longer setting time in SBR. Conversely, the biodegradation rate of all aerobic digesters demonstrates a similar trend (Fig. 1). These biodegradation rates which distinct from COD removal were determined based on the mixed effluent and it represents the fraction of organic matter which been utilized by microorganisms. Previous studies [4], [5] only reported the COD removal of anaerobically digested POME after aerobic treatment hence the corresponding biodegradation rates of anaerobically digested POME at different conditions were questionable. The COD removal is a combination of both biological COD utilization (biodegradation) and physical COD reduction (settling). It is important to distinguish these two terms especially when COD value is need for bio-kinetic evaluation. The increased biodegradation rate at HRT of 12 days implies the increasing OLR provide more food to stimulate the microorganisms' activities. The biodegradation rate of each aerobic digester showed a tendency to fall with a further increase of OLR [4]. The biodegradation rates observed along the experiment were 32.2 to $42.5 \%, 21.4$ to $38.7 \&$ and 17.1 to $43.3 \%$ for AeD-R, AeD-M and AeD-T respectively. This revealed that there more biodegradable organic matters, such as volatile fatty acids, organic compounds and residue oil, remained in $\mathrm{R}$ compared to $\mathrm{M}$ and $\mathrm{T}$ due to lower biodegradation rate at room temperature. It is necessary to conduct further analysis to identify the remaining organic compounds in anaerobically digested POME as well as to evaluate the corresponding impact of these organic compounds in aerobic post-treatment. By excluding the effect of variation of influent COD concentrations, it is cleared that, at the best practice, only less than half of the organic matters are biodegradable under aerobic condition despite the other half were removed by settling. Overall, thermophilic digested POME is slightly more accessible to aerobic biodegradation which may be due the advanced solubilization and hydrolysis of organic matters in thermophilic anaerobic digestion. However, there are limited investigations reported the similar observations. Further study should be focus on analyzing the chemical components and physical properties of anaerobically digested POME and those after aerobic post-treatment.

\begin{tabular}{|c|c|c|c|c|c|}
\hline Aerobic digester & Parameter & $\mathrm{HRT}=18 \mathrm{~d}$ & $\mathrm{HRT}=12 \mathrm{~d}$ & $\mathrm{HRT}=9 \mathrm{~d}$ & $\mathrm{HRT}=7.2 \mathrm{~d}$ \\
\hline \multirow{5}{*}{ AeD-R } & $\mathrm{pH}$ & $8.9 \pm 0.1$ & $8.9 \pm 0.1$ & $8.9 \pm 0.1$ & $9.0 \pm 0.1$ \\
\hline & $\mathrm{DO}, \mathrm{mg} / \mathrm{L}$ & $5.74 \pm 0.17$ & $4.73 \pm 0.38$ & $4.40 \pm 0.27$ & $4.92 \pm 0.30$ \\
\hline & MLVSS, g/L & $3.00 \pm 0.50$ & $2.64 \pm 0.82$ & $5.18 \pm 0.32$ & $5.12 \pm 0.28$ \\
\hline & $\mathrm{OLR}, \mathrm{g} \mathrm{COD} / \mathrm{L} / \mathrm{d}$ & $0.47 \pm 0.04$ & $0.89 \pm 0.10$ & $1.34 \pm 0.08$ & $1.55 \pm 0.16$ \\
\hline & F/M, g COD/g MLVSS & $0.16 \pm 0.03$ & $0.37 \pm 0.14$ & $0.26 \pm 0.02$ & $0.30 \pm 0.02$ \\
\hline \multirow{5}{*}{ AeD-M } & $\mathrm{pH}$ & $8.9 \pm 0.0$ & $9.0 \pm 0.0$ & $9.0 \pm 0.0$ & $9.0 \pm 0.0$ \\
\hline & $\mathrm{DO}, \mathrm{mg} / \mathrm{L}$ & $5.99 \pm 0.20$ & $4.56 \pm 0.29$ & $4.24 \pm 0.55$ & $4.78 \pm 0.36$ \\
\hline & MLVSS, g/L & $4.31 \pm 0.13$ & $2.21 \pm 0.40$ & $4.90 \pm 0.05$ & $5.13 \pm 0.18$ \\
\hline & OLR, g COD/L/d & $0.57 \pm 0.06$ & $0.84 \pm 0.02$ & $1.17 \pm 0.03$ & $1.44 \pm 0.08$ \\
\hline & F/M, g COD/g MLVSS & $0.13 \pm 0.00$ & $0.37 \pm 0.07$ & $0.24 \pm 0.00$ & $0.28 \pm 0.01$ \\
\hline \multirow{5}{*}{ AeD-T } & $\mathrm{pH}$ & $8.9 \pm 0.0$ & $9.0 \pm 0.1$ & $9.0 \pm 0.0$ & $9.0 \pm 0.0$ \\
\hline & $\mathrm{DO}, \mathrm{mg} / \mathrm{L}$ & $5.84 \pm 0.33$ & $4.52 \pm 0.24$ & $3.83 \pm 0.54$ & $4.95 \pm 0.20$ \\
\hline & MLVSS, g/L & $2.79 \pm 0.19$ & $1.62 \pm 0.19$ & $4.12 \pm 0.20$ & $3.96 \pm 0.29$ \\
\hline & $\mathrm{OLR}, \mathrm{g} \mathrm{COD} / \mathrm{L} / \mathrm{d}$ & $0.39 \pm 0.01$ & $0.74 \pm 0.01$ & $1.21 \pm 0.11$ & $1.39 \pm 0.04$ \\
\hline & F/M, g COD/g MLVSS & $0.14 \pm 0.01$ & $0.46 \pm 0.06$ & $0.29 \pm 0.01$ & $0.35 \pm 0.03$ \\
\hline
\end{tabular}

Based on Fig. 2., it can be evidently seen that the TSS concentration in digested POME significantly influences the MLSS concentration of aerobic digesters. There are very limited portion of TSS could be biodegraded espectically at higher OLR because the POME were previously anerobically degraded. Even though, most of the suspended solids will be settled after 1 hour. Previously, Metcalf and Eddy [6] suggested a desired biomass concentration of 3000 to 6000 $\mathrm{mg} / \mathrm{L}$ for effective functioning of an activated sludge reactor. In fact, this amount of biomass seems not sufficient when treating anaerobic digested POME due to its high organic strength [4]. The findings reported in the literature showed an optimum performance of sequencing batch reactor operated at MLVSS of 17500 to $20000 \mathrm{mg} / \mathrm{L}$ to achieved COD removal of 98.2 to $98.9 \%$.
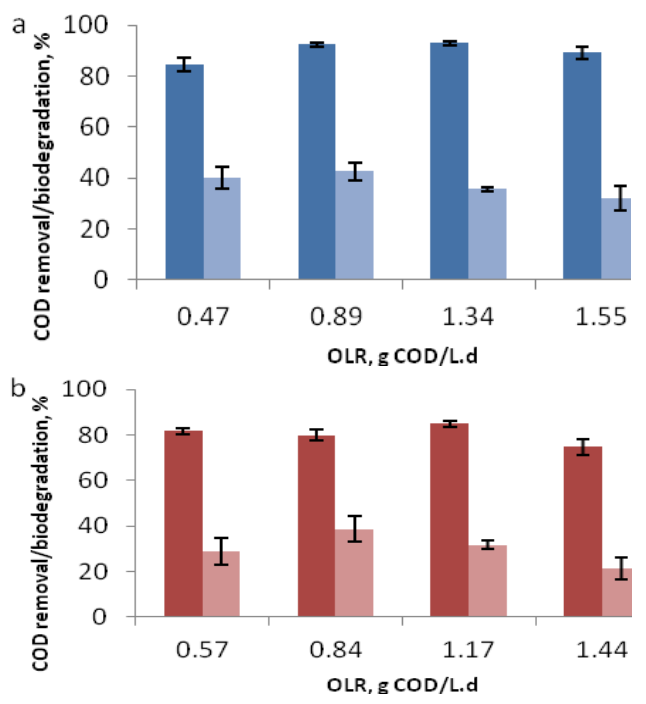


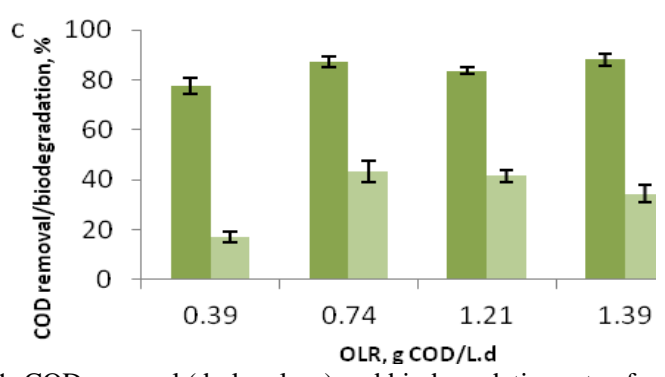

Fig. 1. COD removal (dark colour) and biodegradation rate of aerobic digester (a) Ae-R, (b) Ae-M and (c) Ae-T, respectively.

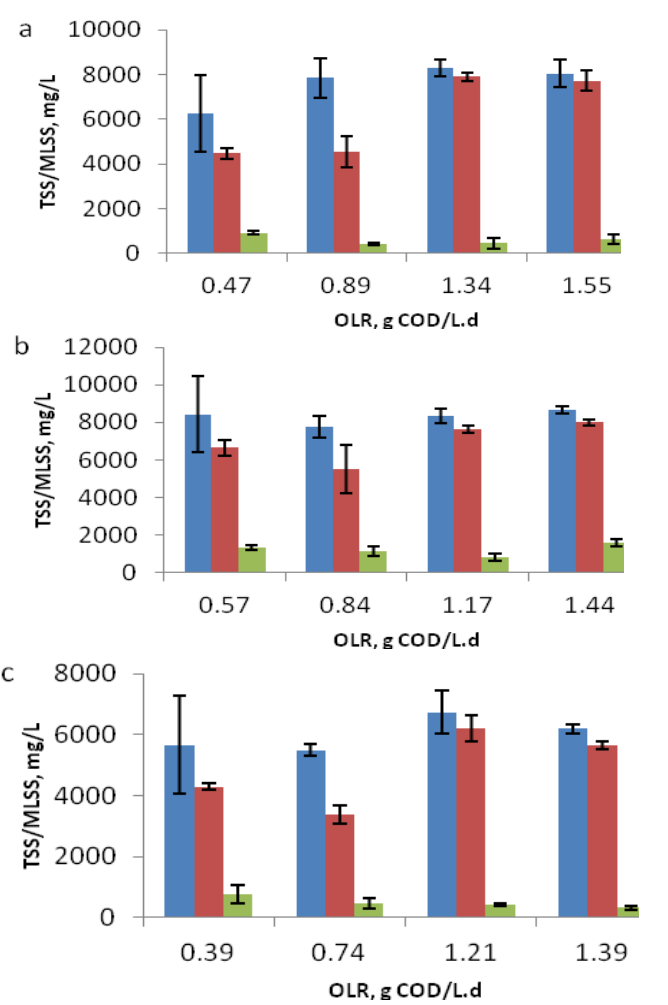

Fig. 2. TSS or MLSS concentration of digested POME (blue), mixed effluent (red) and effluent supernatant (green) in aerobic digester (a) Ae-R, (b) Ae-M and (c) Ae-T, respectively.

It appears that AeD-R and AeD-T able to produce effluent with better settling capability. However, the effluent supernatant of all aerobic digesters barely meet the local discharge standard of TSS concentration of $400 \mathrm{mg} / \mathrm{L}$. After two hours of settling, the TSS remained in the effluent supernatant of AeD-R, AeD-M and AeD-T were 410 to 910 $\mathrm{mg} / \mathrm{L}, 835$ to $1590 \mathrm{mg} / \mathrm{L}$ and 315 to $740 \mathrm{mg} / \mathrm{L}$, respectively. These values are much high than previous research reported only 150 to $250 \mathrm{mg} / \mathrm{L}$ TSS remained in the final effluent. This remarkable TSS removal may be caused by a higher MLVSS concentration as well as longer settling time.Besides that, the TSS and VSS removals (Fig. 3a, b and c) were less affected by inclined OLR which is coincided with COD removal aforementioned. The TSS removals for AeD-R, AeD-M and AeD-T were 85.5 to $94.8 \%, 81.6$ to $90.0 \%$ and 86.9 to $94.9 \%$, respectively. Hence, higher OLR could be applied bcacause the aerobic digesters have not yet to reach its maximum operational limit.

Generally, a polishing system applied as tertiary treatment of POME after anaerobic and aerobic degradation. The combination of these biological treatment system required large surface area to allocate a series of pond or lagoon due to longer operational HRT. Thus, physio-chemical treatment such as menbrane filtration, advance oxidation and coagulation-flocculation process could be included to emphasize the discharge limit compliance [7].
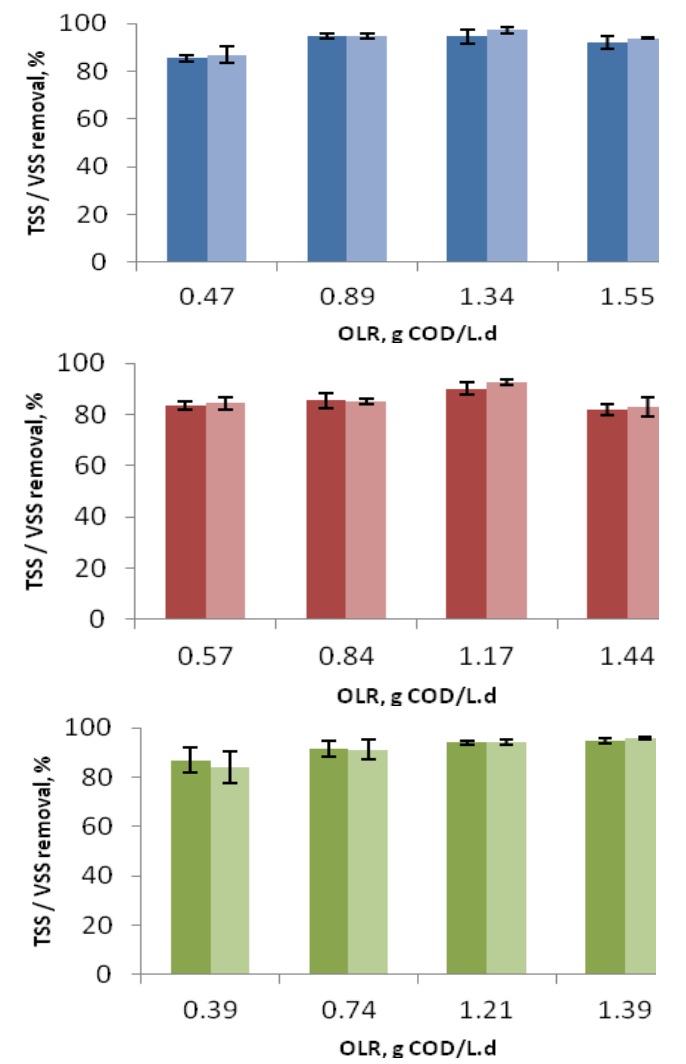

Fig. 3. TSS (dark colour) and VSS (light colour) removal in aerobic digesters (a) Ae-R, (b) Ae-M and (c) Ae-T, respectively.

\section{CONCLUSION}

The well controlled aerobic digester could be an effective post-treatment of different anaerobically digested POME which can achieve appreciable COD, TSS and VSS removal. Both AeD-R and AeD-T demonstrated slightly better COD, TSS and VSS removal than Ae-M. This study shows that the aerobic treatment of different anaerobically digested POME could be operated at HRT up to 7.2 day. Further investigation should be focused on optimization of aerobic post-treatment of different anaerobically digested POME. Comprehensive physio-chemical, microbiological and morphological analysis should be conducted in order to determine limiting factors of the corresponding process.

\section{REFERENCES}

[1] T. Y. Wu, M. Abdul Wahab, J. M. Jahim, and N. Anuar, "Pollution control technologies for the treatment of palm oil mill effluent (POME) through end-of-pipe processes," Journal of Environmental Management, vol. 91, pp. 1467-1490, 2010.

[2] K. K. Chin, S. Lee, and H. H. Mohammad, "A study of palm oil mill effluent treatment using a ponding system," Water Science and Technology, vol. 34, pp. 119-123, 1996.

[3] K. Vijayaraghavan, D. Ahmad, and M. E. A. Aziz, "Aerobic treatment of palm oil mill effluent," Journal of Environmental Management, vol. 82, pp. 24-31, 2007.

[4] Y. J. Chan, M. F. Chang, and C. L. Law, "Biological treatment of anaerobically digested palm oil mill effluent (POME) using a lab-scale sequencing batch reactor (SBR)," Journal of Environmental Management, vol. 91, pp. 1738-1746, 2010.

[5] Y. J. Chan, M. F. Chang, and C. L. Law, "Effect of temperature on aerobic treatment of anaerobically digested palm oil mill effluent 
(POME)," Industrial \& Engenerring Chemistry Research, vol. 49, pp. 7093-7101, 2010.

[6] G. Tchobanoglous, F. L. Burton, H. D. Stensel, Metcalf, and Eddy, Wastewater Engineering: Treatment and Reuse, 4th ed., Metcalf and Eddy Inc, 2003.

[7] W. L. Liew, M. A. Kassim, K. Muda, S. K. Loh, and A. C. Affam, "Conventional methods and emerging wastewater polishing technologies for palm oil mill effluent treatment; A review", Journal of Environmental Management, vol. 149, pp. 222-235, 2015.

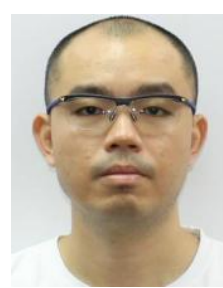

Kian Weng Chou was born in Malaysia on March 19 1985. He held his bachelor's and master degree in environmental technology in Universiti Sains Malaysia in 2008 and 2012, respectively. Currently, he is conducting his $\mathrm{PhD}$ studies in School of Industrial Technology, Universiti Sains Malaysia. His current interests include anaerobic and aerobic treatment of palm oil mill effluent.

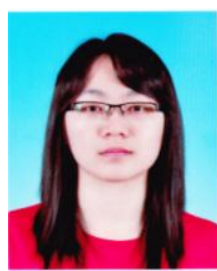

Siew Wei Tan was born in Malaysia on March 31, 1991. She holds a bachelor degree in environmental technology from Universiti Sains Malaysia in 2014 Currently she is a process engineer at Fuji Electric (M) Sdn. Bhd., Malaysia.

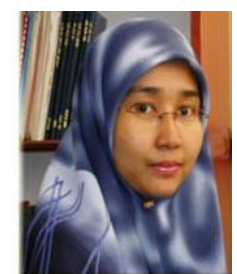

Norli Ismail was born in Malaysia on September 25 , 1971. She holds a bachelor degree in environmental science from Universiti Putra Malaysia, masters degree in chemical processes and a $\mathrm{PhD}$ in environmental technology from Universiti Sains Malaysia.

She joins the School of Industrial Technology, Universiti Sains Malaysia as a lecturer attached to Environmental Technology Division. Now she occupies the position of a professor at the same department.

She has research experienced collaboration on hydrothermal gasification of palm oil mill effluent (POME) with Osaka Gas Ltd., Japan, at the Eco-energy department. Her current research fields of interest are an enhancement of biogas production from agricultural biomass through anaerobic fermentation processes and bioflocculant production for water, wastewater and solid waste treatment. 